\title{
Targeting the endoplasmic reticulum in prion disease treatment: breakthroughs and challenges
}

This article was published in the following Dove Press journal:

Research and Reports in Biochemistry

23 January 2015

Number of times this article has been viewed

\section{Soshi Kanemoto \\ Department of Biochemistry, Institute of Biomedical and Health Sciences, Hiroshima University, Hiroshima, Japan}

\begin{abstract}
Prion diseases are infectious, predominantly fatal neurodegenerative diseases characterized by abnormal prion protein ( $\mathrm{PrP}$ ) accumulation and neuronal loss. Studies on experimental animal models and clinical features of human prion diseases have shown unfolded $\operatorname{PrP}$ accumulation results in endoplasmic reticulum (ER) stress. While ER stress-mediated apoptosis is responsible for neuronal loss in prion diseases, ER stress also activates the unfolded protein response (UPR) in an effort to restore ER homeostasis. Of the UPR signaling pathways, the PERK-eIF $2 \alpha$ pathway is implicated in the pathogenesis of prion diseases. The proteasome protein degradation system is also activated during the UPR. Increasing evidence indicates that proteasome and autophagy activities are affected in prion diseases. These findings suggest that ER stress/UPR contributes to the onset of prion diseases. Hence, strategies that target the ER are useful approaches in treating prion diseases. Additionally, immunotherapeutic approaches for prion diseases have been developed in recent decades. Single-chain fragment variable antibodies targeting the accumulation of $\mathrm{PrP}$ are also beneficial in the prevention of abnormal PrP propagation. This review discusses pathogenic mechanisms related to the ER and potential strategies for treating prion diseases.
\end{abstract}

Keywords: prion, endoplasmic reticulum, unfolded protein response, therapy

\section{Introduction: pathogenesis and clinical manifestations of transmissible spongiform encephalopathies}

Transmissible spongiform encephalopathies, also well-recognized as prion diseases, include Creutzfeldt-Jakob disease (CJD), Gerstmann-Sträussler-Scheinker syndrome (GSS), fatal familial insomnia (FFI), and Kuru in humans, scrapie in sheep and goats, transmissible mink encephalopathy in minks, chronic wasting disease in deer and elk, and bovine spongiform encephalopathy in cattle. ${ }^{1}$ These diseases are both fatal and infectious, and are characterized by similar features of pathogenesis. Common features of prion disease pathology are the deposition of abnormal forms of cellular prion proteins (PrP), spongiform vacuolation, severe neuronal loss, and astrocytosis and microgliosis. PrP itself is widely considered the infectious source.

Normally, newly synthesized PrP undergoes several post-translational modifications within the endoplasmic reticulum (ER) and Golgi apparatus to give rise to mature PrP, which is localized at the cell surface through a glycosylphosphatidylinositol (GPI) anchor. ${ }^{2}$ PrP also contains a conserved hydrophobic sequence that can be oriented in either direction at the lipid bilayer, resulting in another two different transmembrane forms designated ${ }^{\mathrm{Ctm} P r P}$ and ${ }^{\mathrm{Ntm} P r P}$. In this case, a centrally positioned, highly
Correspondence: Soshi Kanemoto of Biomedical and Health Sciences, Hiroshima University, 1-2-3 Kasumi, Minami-ku, Hiroshima, 734-8553, Japan Tel +8| $822575|3|$

Fax +81822575134

Email soshikanemoto@hiroshima-u.ac.jp 
conserved hydrophobic region in ${ }^{\mathrm{Ctm}} \mathrm{PrP}$ and ${ }^{\mathrm{N} t m} \mathrm{PrP}$ acts as a transmembrane anchor, and directs the C-terminal and $\mathrm{N}$-terminal regions, respectively, into the lumen of the ER. ${ }^{3}$ PrP has at least two structural forms, the normal cellular form $\left(\mathrm{PrP}^{\mathrm{C}}\right)$ and the misfolded form $\left(\mathrm{PrP}^{\mathrm{Sc}}\right)$. The two isoforms have identical amino acid sequences, but differ in their monomeric conformation and state of aggregation. $\mathrm{PrP}^{\mathrm{C}}$ is a soluble, $\alpha$-helix-rich protein, while $\mathrm{PrP}^{\mathrm{Sc}}$ is an insoluble protein, high in $\beta$-sheet structure, and partially resistant to proteolytic digestion. ${ }^{1,4-7} \mathrm{PrPSc}^{\mathrm{Sc}}$ functions as a template promoting the conversion of $\mathrm{PrP}^{\mathrm{C}}$ to abnormal $\mathrm{PrP}^{\mathrm{Sc}}$ structural forms. ${ }^{8-10}$ Many studies have shown $\mathrm{PrP}^{\mathrm{Sc}}$ production in vitro in the absence of genetic material. In such situations, $\mathrm{PrP}^{\mathrm{Sc}}$ is able to self-replicate by facilitating the conversion of $\mathrm{PrP}^{\mathrm{C}}$ to $\mathrm{PrP}^{\mathrm{Sc}} \cdot{ }^{11-14} \mathrm{PrP}^{\mathrm{Sc}}$ replication starts from the formation of an ordered nucleus as the seeds and then proceeds to polymerization to form aggregates. ${ }^{15}$ To date, this concept is widely accepted. Interestingly, $\operatorname{PrP}^{\mathrm{C}}$ knockout mice infected with an infectious PrP species did not display neurodegeneration, suggesting the loss of PrP was not involved in disease pathogenesis. ${ }^{16,17}$ Some studies indicated that $\mathrm{PrP}^{\mathrm{C}}$ functions as a high-affinity copper-binding protein. ${ }^{18-20}$ Moreover, $\mathrm{PrP}^{\mathrm{C}}$ regulates $N$-methyl-D-aspartate receptors, and might be involved in pathogenesis of Alzheimer's disease (AD). ${ }^{21,22}$ However, the true function of PrPs is debatable.

Point mutations or insertions in the PrP gene (known as the PRNP gene) are responsible for genetic prion diseases including familial CJD, GSS, and FFI. ${ }^{23}$ Such mutations in the $P R N P$ gene are likely to cause misfolding and aggregation of PrP. Sporadic prion diseases, which include the majority of CJD and sporadic fatal insomnia cases, are believed to arise from spontaneous misfolding of normal $\operatorname{PrP}^{\mathrm{C}}$ or from rare somatic mutations in the PRNP gene. ${ }^{24}$

The clinical manifestations of human prion disease vary according to disease subtype. For example, GSS is characterized by chronic cerebellar ataxia with dementia, and the presence of multicentric amyloid plaques, while CJD is associated with subacute dementia and motor abnormalities, and with widespread spongiform degeneration in the cerebral cortex, striatum, and cerebellum. FFI shows a subacute condition with untreatable insomnia, dysautonomia, and severe selective atrophy of the anterior ventral and mediodorsal nuclei of the thalamus. ${ }^{25}$

\section{Role of the ER and quality control systems in prion disease Unfolded protein response}

The ER is a specialized organelle in which newly-synthesized secreted or membrane proteins are folded and modified.
ER stress is defined as the accumulation of unfolded and/or misfolded proteins in the ER in response to nutrient deprivation, perturbation of intracellular calcium homeostasis, oxidative stress, or the expression of mutated proteins, for example. ER stress activates a regulatory system termed the unfolded protein response (UPR) to manage defective proteins in the ER. ${ }^{26}$ The UPR includes three signaling pathways: 1) translational attenuation to inhibit the further generation of unfolded proteins; 2) facilitating refolding of unfolded proteins by the induction of ER molecular chaperones; and 3) activating ER-associated degradation to degrade unfolded proteins accumulated in the ER via the ubiquitin proteasome system (UPS). If the aforementioned strategies fail, the cells enter into ER stress-induced apoptosis. The three major transducers of the UPR are PKR-like ER kinase (PERK), inositol-requiring enzyme 1 (IRE1), and activating transcription factor 6 (ATF6). PERK is an ER transmembrane protein kinase which phosphorylates eukaryotic initiation factor- $2 \alpha$ (eIF $2 \alpha)$ to induce translational attenuation. ${ }^{27}$ The prolonged suppression of protein synthesis by inactive phosphorylated eIF $2 \alpha$ (P-eIF2 $\alpha$ ) is not conducive to cell survival, hence the translational process is restored through GADD34-mediated dephosphorylation of P-eIF $2 \alpha .{ }^{28}$ IRE1 is an ER transmembrane protein containing endoribonuclease and cytoplasmic protein kinase domains. Activated IRE1 catalyzes the unconventional splicing of X-box binding protein 1 (XBP-1) messenger RNA, which encodes a basic leucine zipper transcription factor. The spliced form of XBP-1 protein upregulates the synthesis of ER-resident molecular chaperones, including GRP78/BiP. ${ }^{29,30}$ ATF6, a member of the CREB/ATF family, is a type II ER transmembrane protein which mediates transcriptional induction in response to ER stress. The membrane-anchored ATF6 is cleaved at the transmembrane region in response to ER stress, and the processed N-terminus of ATF6 is translocated to the nucleus where it promotes the transcription of molecular chaperones, such as GRP78/BiP and GRP94. ${ }^{31-33}$

Recently, ER stress has been implicated in the pathogenesis of prion diseases. Elevated levels of ER stress markers, including GRP78/BiP, GRP94, and GRP58, were observed in the cerebral cortex of prion disease patients, and in prion disease mouse models. ${ }^{34-36}$ Purified $\mathrm{PrP}^{\mathrm{Sc}}$ extracted from the brain of scrapie-infected mice invoked ER stress and induced the release of intracellular $\mathrm{Ca}^{2+}$ from ER stores. ${ }^{37}$ It is believed that alteration of $\mathrm{ER} \mathrm{Ca}^{2+}$ homeostasis and subsequent ER stress are involved in the progression of prion disease. ${ }^{36,38}$ $\mathrm{PrP}^{\mathrm{Sc}}$-mediated release of $\mathrm{Ca}^{2+}$ from the ER to the cytosol induces loss in mitochondrial membrane potential, increases 
reactive oxygen species levels, and results in apoptosis. ${ }^{38-40}$ $\mathrm{PrP}^{\mathrm{Sc}}$ is also responsible for protein accumulation in the ER, resulting in ER stress-induced apoptosis. ${ }^{41}$ During PrP infection, ER stress occurs and translocation of nascent $\operatorname{PrP}$ reduces, then this leads to neurodegeneration. ${ }^{42}$ In contrast, Nunziante et al showed that ER stress or proteasomal dysfunction enhances trafficking of PrP aggregates through the secretory pathway and raises accumulation of $\mathrm{PrP}^{\mathrm{Sc}}$ significantly in persistently prion-infected cells.$^{43}$ Thus, trafficking of PrP during ER stress in PrP infection is open to dispute.

\section{Proteasome system}

Ma et al proposed that UPS might play an important role in the pathogenesis of prion disease. ${ }^{44}$ Proteasomes are large multicatalytic, cytoplasmic and nuclear protease complexes essential for cell survival. Additionally, the UPS is predominantly responsible for non-lysosomal protein degradation. ${ }^{45-48}$ Inhibition of the UPS by proteasome inhibitors leads to accumulation of $\mathrm{PrP}^{\mathrm{Sc}}$-like species in cells. $\mathrm{PrP}^{\mathrm{Sc}}$ generated from misfolded $\mathrm{PrP}^{\mathrm{C}}$ was retro-transported to the cytosol and degraded by proteasomes. ${ }^{44}$ The use of proteasome inhibitors induced conversion of accumulated $\operatorname{PrP}^{\mathrm{C}}$ to $\mathrm{PrP}^{\mathrm{Sc}}$-like species, which persisted after removal of inhibitor, and led to apoptosis and infection of neighboring cells. ${ }^{44}$ Some studies have suggested that functional impairment of the UPS is related to Prion disease. ${ }^{49,50} \mathrm{~A}$ null mutation in the gene encoding Mahogunin, a putative E3 ubiquitin ligase, is responsible for spongiform-like neurodegeneration, which mimics prion disease histologically. ${ }^{51,52}$ Moreover, E3 ubiquitin ligase Hectd2 was linked with prion disease incubation time in mice, and associated with sporadic variant CJD and Kuru. ${ }^{53}$

Additionally, three PrP mutations (V203I, E211Q, and Q212P) associated with familial prion disease caused PrP accumulation in the cytosol in response to proteasome inhibition, resulting in aggresome formation. ${ }^{54}$ Following mild proteasome inhibition, PrP-infected neuronal cells succumbed to apoptosis, forming large $\mathrm{PrP}^{\mathrm{Sc}}$ aggresomes, which complexed with HSC70, ubiquitin, proteasome subunits, and vimentin. ${ }^{55}$ Thus, many studies have suggested that UPS is impaired in neurodegenerative diseases, however, the precise mechanism is still to be elucidated.

\section{Autophagy}

Recent evidence has emerged that autophagy plays a key role in prion disease. Autophagy is a fundamental bulk degradation system for cellular organelles and cytosolic proteins. Autophagy is also involved in UPR and is triggered by ER stress. ${ }^{56-58}$ The importance of autophagy has been recognized in a number of neurodegenerative diseases including prion disease, $\mathrm{AD}$, Parkinson's disease (PD), and Huntington's disease (HD). ${ }^{59,60}$ Increased number of autophagosomes, or autophagic vacuoles (AVs), is a common feature of many neurodegenerative diseases. Large AVs were observed in neurons of CJD model mice and scrapie-infected hamsters, with similar ultrastructural features of autophagy observed for both experimental models. Moreover, multivesicular bodies and AVs were detected in prion-infected neurons and in various forms of human prion disease. ${ }^{61-63}$ Although colocalization of $\mathrm{PrP}^{\mathrm{Sc}}$ with autophagosomes was not observed in the brain of scrapie-infected hamster, $\operatorname{PrP}^{\mathrm{Sc}}$ was colocalized with autophagosomes in prion-infected cells, which had been treated with bafilomycin A, an inhibitor of autolysosome formation. ${ }^{64}$ Mutant PrP colocalized with autophagosomes in a Neuro-2a cell line expressing CJD-associated PrP mutants. ${ }^{65}$ Chronic administration of rapamycin, an autophagy-inducing agent, to transgenic $\operatorname{Tg}(\mathrm{PrP}-\mathrm{A} 116 \mathrm{~V})$ mice, which model genetic prion disease, prevented the deposition of $\mathrm{PrP}^{\mathrm{Sc}}$ and significantly delayed disease onset. ${ }^{66}$ Imatinib treatment of prion-infected mice delayed $\mathrm{PrP}^{\mathrm{Sc}}$ invasion of neural cells and the onset of clinical disease, by activating lysosomal degradation of $\mathrm{PrP}^{\mathrm{Sc}}$ at the initial stage of peripheral infection. ${ }^{67}$ Additionally, both lithium and trehalose improved $\mathrm{PrP}^{\mathrm{Sc}}$ clearance by induction of autophagy in prion-infected cells, ${ }^{68,69}$ while $\mathrm{PrPs}^{\mathrm{Sc}}$ levels increased in cells treated with autophagy inhibitors. ${ }^{60,68-70}$

There is increasing evidence that proteasome inhibition induces autophagy, and this provides a complementary pathway for proteasome impairment. However, once the activated autophagic system reaches saturation, autophagy appears to be impaired. Autophagy has been shown to go awry in neurodegenerative diseases including $\mathrm{AD}, \mathrm{PD}$, HD, and amyotrophic lateral sclerosis. ${ }^{71}$ Therefore, more detailed analyses are required to clarify whether a balance exists between the proteasome system and autophagy in vivo.

\section{Elucidating ER-related cellular and biochemical mechanisms that lead to neuronal dysfunction}

Many studies have demonstrated synaptic dysfunction and degeneration, in addition to neuronal loss in prion disease mouse models. ${ }^{72-80} \mathrm{PrP}^{\mathrm{C}}$ misfolding and its subsequent accumulation in the ER is believed to be responsible for synaptic failure. Moreno et al discovered a link between PrP accumulation in the hippocampus of mice infected 
with Rocky Mountain Laboratory (RML) prions, and the enhanced translational attenuation pathway of the UPR. ${ }^{80}$ Sustained translational attenuation by phosphorylation of PERK and its target eIF2 $\alpha$, resulted in synaptic failure and neuronal loss, whereas enhancement of translational recovery in the hippocampi of RML-infected mice was neuroprotective. Overexpression of the eIF $2 \alpha$-specific phosphatase GADD34 rescued synaptic deficits and neuronal loss. Additionally, RNA interference mediated by lentivirally expressed short hairpin RNA for PrP reduced PrP levels and prevented synaptic degeneration. Conversely, salubrinal, an inhibitor of P-eIF2 $\alpha$ dephosphorylation, increased P-eIF $2 \alpha$ levels and aggravated neurodegeneration in prion-infected mice. Inhibition of PERK phosphorylation by GSK2606414, a selective inhibitor of PERK, also provided a neuroprotective effect in prion-infected mice ${ }^{81}$ Collectively, these results suggest the PERK-eIF2 $\alpha$ pathway regulates pathogenesis of prion diseases.

PrP accumulation caused the ER stress-associated release of calcium from the ER, which leads to hyperactivation of calcium dependent phosphatase calcineurin $(\mathrm{CaN}) .{ }^{82}$ Activated $\mathrm{CaN}$ mediated neurodegeneration in prion-infected mice. Interestingly, the administration of $\mathrm{CaN}$ inhibitor FK506 to prion-infected mice reduced the severity of clinical abnormalities and increased life-spans. Thus, $\mathrm{PrP}^{\mathrm{Pc}}$-mediated perturbations to ER calcium homeostasis have implications on the pathogenesis of prion diseases.

CtmPrP possesses an uncleaved signal peptide and GPI anchor, and its retention in the ER or Golgi apparatus is dependent on cell type. ${ }^{83}$ Recently, Wang et al demonstrated recombinant mutant PrP associated with familial CJD induced ${ }^{\mathrm{Ctm} P r P}$ retention in the ER, upregulated the levels of GRP78, GRP58, and PERK, and led to ER stress-induced apoptosis in SH-SY5Y cells. ${ }^{41}$

These findings indicate that ER stress and the UPR are involved in neuronal dysfunction in prion diseases. Within murine models of prion disease, however, there are mice in which ER stress or the UPR are not triggered. One such example can be found in $\operatorname{Tg}(\mathrm{PG} 14)$ mice that express a mutant PrP with a nine-octapeptide repeat insertion associated with a genetic prion disease. Neither an increase in UPR-regulated gene expression, nor activation of the PERK-eIF2 $\alpha$ pathway, was observed for $\mathrm{Tg}(\mathrm{PG} 14)$ mice. ${ }^{84}$ Additionally, CaN activity was reduced, rather than promoted, in this mouse model. ${ }^{85}$ These results suggest that pathogenesis of prion diseases is not explained by ER stress alone. Different pathogenic mechanisms might account for the observed heterogeneity in prion diseases. More extensive analyses are required to fully understand neuronal dysfunction and pathogenesis of prion diseases.

\section{Discovery of ER-retained antibodies that disrupt PrPC accumulation in the $E R$, and novel immunotherapeutic strategies}

The development of antibodies directed against PrP is one approach in the treatment of prion diseases. In the last decade, single-chain fragment variable ( $\mathrm{scFv}$ ) antibodies have been developed for use in passive immunotherapy. ${ }^{86} \mathrm{scFvs}$ are produced by fusing the variable region in heavy $\left(\mathrm{V}_{\mathrm{H}}\right)$ and light $\left(\mathrm{V}_{\mathrm{L}}\right)$ chain fragments of an immunoglobulin $\mathrm{G}$ connected with an appropriate linker. ${ }^{87}$ scFvs have several advantages over chimeric or humanized antibodies, for example, little immunogenicity, no complement fixation, and better tissue penetration due to their small size. Moreover, scFvs tend to have shorter half-lives. Additionally, because scFvs do not require glycosylation, they can be produced in a bacterial expression system. ${ }^{88}$ Antibodies against $\mathrm{PrP}^{\mathrm{C}}$ indirectly facilitate the clearance of $\mathrm{PrP}^{\mathrm{Sc}}$, inhibit the conversion of $\mathrm{PrP}^{\mathrm{C}}$ to $\mathrm{PrP}^{\mathrm{Sc}}$, and promote degradation of $\mathrm{PrP}^{\mathrm{C}} .89$ To date, at least 20 studies have used scFvs to target PrPs. ${ }^{88}$ Many of these scFvs inhibited PrP aggregation and impaired $\mathrm{PrP}^{\mathrm{Sc}}$-associated cellular toxicity. Cardinale et al produced ER-retained anti-prion scFv antibodies, which confined $\mathrm{PrP}^{\mathrm{C}}$ to the ER, prevented $\mathrm{PrP}^{\mathrm{C}}$ translocation to the cell surface, and inhibited $\mathrm{PrP}^{\mathrm{Sc}}$ accumulation in PC12 cells. ${ }^{90}$

The targeting of scFvs to specific sites within cells is achieved by in-frame fusion with intracellular trafficking sequences to scFvs. To generate ER-retained scFvs, they were designed with a signal sequence at the $\mathrm{N}$-terminus and a retention peptide, KDEL (Lys-Asp-Glu-Leu), at the C-terminus. ${ }^{91}$ In the same way, scFvs can be targeted to cytoplasm, nucleus, trans-Golgi, and plasma membrane with using specific trafficking sequences and retention signals for each organelle. ${ }^{92}$ The delivery of scFvs would be attained by either adenoassociated viral vectors ${ }^{93}$ or cell lines expressing scFvs. ${ }^{89,94,95}$ Delayed onset of prion disease was observed in a mouse model treated with anti-PrP ${ }^{\mathrm{C}}$ recombinant adeno-associated viral scFvs. ${ }^{93}$ Also, secreted anti-PrP scFvs produced by cell lines prevented $\mathrm{PrP}^{\mathrm{Sc}}$ formation ${ }^{89,94}$ and significantly extended the life-span of scrapie-infected mice. ${ }^{95}$

Another strategy in the treatment of prion diseases would be the use of antibodies targeted against the laminin receptor (LRP/LR). The LRP/LR is thought to function as a receptor for $\mathrm{PrP}^{\mathrm{C}}$ and $\mathrm{PrP}^{\mathrm{Sc}},{ }^{96,97}$ and it has been shown to 
play a critical role in the infection process of PrP.98,99 The LRP/LR is necessary for internalization of bovine $\mathrm{PrP}^{\mathrm{Sc}}$ in human cells, ${ }^{100}$ and the administration of anti-LRP/LR scFvs to scrapie-infected mice reduced peripheral levels of $\mathrm{PrP}^{\mathrm{Sc}}$, even though survival period was not prolonged. ${ }^{101,102}$

\section{Prospects for targeting the ER, and early diagnosis}

As detailed above, evidence supporting involvement of ER stress in prion disease pathogenesis is increasing (Figure 1). Therefore, strategies that target the ER should be explored when considering therapeutic approaches to prion diseases. Prolonged phosphorylation of PERK and eIF $2 \alpha$ resulted in synaptic failure and neuronal loss in RML prion-infected mice.$^{80}$ Conversely, the overexpression of GADD34, or the inhibition of PrP synthesis by RNA interference, rescued these defects. Moreover, the PERK inhibitor GSK2606414 inhibited clinical symptoms of disease in prion-infected mice ${ }^{81}$ Hence, strategies that suppress the PERK-eIF2 $\alpha$ pathway, such as activation of GADD34, would be beneficial in prion disease therapy. Interestingly, salubrinal, which activates the PERK-eIF2 $\alpha$ pathway of the UPR by inhibiting dephosphorylation of eIF2 $\alpha$, exacerbated disease presentation ${ }^{80}$ Salubrinal reduced $\alpha$-synuclein accumulation in PD models, ${ }^{103-105}$ prevented amyloid $\beta$-induced neuronal death, ${ }^{106}$ reduced protein aggregation caused by $\mathrm{N}$-terminal mutant huntingtin, ${ }^{107}$ and reduced brain damage in a rat model of cerebral ischemia/reperfusion injury. ${ }^{108}$ It is therefore of no surprise that salubrinal has been considered a potential therapeutic agent for ER stress-related neurodegenerative diseases including AD, PD, and HD. As discussed previously, however, the use of salubrinal in the prion disease model had quite the opposite effect. ${ }^{80}$ These findings suggest that

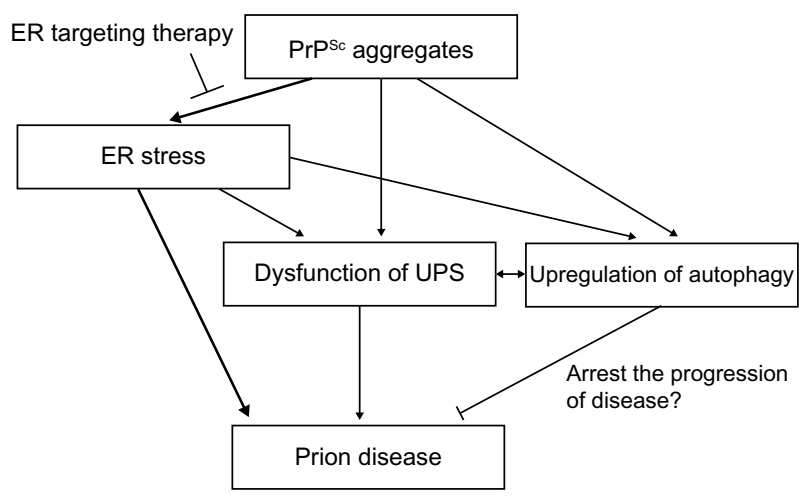

Figure I Overview of the relationship among prion disease, ER stress, UPS, and autophagy.

Abbreviations: ER, endoplasmic reticulum; $\operatorname{PrPS}^{\mathrm{Sc}}$, the misfolded form of prion protein; UPS, ubiquitin proteasome system. a certain amount of fine-tuning depending on aspects of ER stress conditions will be necessary in individual neurodegenerative diseases. ${ }^{109}$ In either case, ER stress is observed for prion diseases, and as such, monitoring of ER stress may be a useful strategy for the early diagnosis of disease.

During the UPR, ER-associated degradation activation results in protein degradation via the UPS. Both proteasome system impairment and enhanced autophagy occur during prion infection (Figure 1). These findings suggest that strategies targeted to proteasomes and/or autophagy should be also considered in the treatment of prion diseases.

In recent years, antibody-based immunotherapy has focused on the development of antibodies that could neutralize the toxicity associated with PrP aggregation. Of these therapies, scFvs have proved the most promising. ER-targeted anti-PrP ${ }^{\mathrm{C}}$ scFvs trapped PrPs in the ER, and blocked the accumulation of $\mathrm{PrPs}^{\mathrm{Sc} .}{ }^{90}$ Anti-LRP/LR scFvs were effective in reducing peripheral $\mathrm{PrP}^{\mathrm{Sc}}$ propagation, but failed to prolong survival of scrapie-infected mice. ${ }^{102}$

Finally, recent experimental studies have provided evidence to indicate dissociation between PrP infectivity and neurotoxicity. ${ }^{110,111}$ To date, it was widely accepted that $\operatorname{PrP}^{\mathrm{Sc}}$ was responsible for both infectivity and neurotoxicity, but the idea that noninfectious $\operatorname{PrP}$ is the true pathogen is gaining momentum. Moreover, it has been reported that PrP oligomers show neurotoxicity rather than $\mathrm{PrP}^{\mathrm{Sc}}$ aggregates in vitro and in vivo. ${ }^{12,113}$ Hence, an approach eliminating only $\operatorname{PrP}^{\mathrm{Sc}}$ aggregates as a treatment for prion disease may not abrogate PrP neurotoxicity. Inclusive of recent concepts, the application of a therapeutic agent in treating prion diseases requires further analysis, and it should include measures for the safe and precise delivery of the agent to the target site.

\section{Acknowledgment}

SK is funded by grant from the Japan Society for the Promotion of Science (Grant Number KAKENHI 25861324).

\section{Disclosure}

The author declares no conflict of interest in this work.

\section{References}

1. Prusiner SB. Prions. Proc Natl Acad Sci U S A. 1998;95(23): 13363-13383.

2. Baldwin MA. Analysis of glycosylphosphatidylinositol protein anchors: the prion protein. Methods Enzymol. 2005;405:172-187.

3. Hegde RS, Mastrianni JA, Scott MR, et al. A transmembrane form of the prion protein in neurodegenerative disease. Science. 1998;279(5352): $827-834$.

4. Griffith JS. Self-replication and scrapie. Nature. 1967;215(5105): 1043-1044. 
5. Prusiner SB. Novel proteinaceous infectious particles cause scrapie. Science. 1982;216(4542):136-144.

6. Zhou Z, Xiao G. Conformational conversion of prion protein in prion diseases. Acta Biochim Biophys Sin. 2013;45(6):465-476.

7. Yuan Z, Zhao D, Yang L. Decipher the mechanisms of rabbit's low susceptibility to prion infection. Acta Biochim Biophys Sin. 2013;45(11): 899-903.

8. Colby DW, Prusiner SB. Prions. Cold Spring Harb Perspect Biol. 2011;3:a006833.

9. Moreno-Gonzalez I, Soto C. Misfolded protein aggregates: mechanisms, structures and potential for disease transmission. Semin Cell Dev Biol. 2011;22(5):482-487.

10. Surewicz WK, Apostol MI. Prion protein and its conformational conversion: a structural perspective. Top Curr Chem. 2011;305: $135-167$.

11. Legname G, Baskakov IV, Nguyen HO, et al. Synthetic mammalian prions. Science. 2004;305(5684):673-676.

12. Castilla J, Saá $P$, Hetz C, Soto C. In vitro generation of infectious scrapie prions. Cell. 2005;121(2):195-206.

13. Deleault NR, Harris BT, Rees JR, Supattapone S. Formation of native prions from minimal components in vitro. Proc Natl Acad Sci U S A. 2007;104(23):9741-9746.

14. Wang F, Wang X, Yuan CG, Ma J. Generating a prion with bacterially expressed recombinant prion protein. Science. 2010;327(5969): $1132-1135$.

15. Come JH, Fraser PE, Lansbury PT Jr. A kinetic model for amyloid formation in the prion diseases: importance of seeding. Proc Natl Acad Sci U SA. 1993;90(13):5959-5963.

16. Büeler H, Aguzzi A, Sailer A, et al. Mice devoid of PrP are resistant to scrapie. Cell. 1993;73(7):1339-1347.

17. Manson JC, Clarke AR, Hooper ML, Aitchison L, McConnell I, Hope J. 129/Ola mice carrying a null mutation in PrP that abolishes mRNA production are developmentally normal. Mol Neurobiol. 1994;8(2-3): 121-127.

18. Brown DR, Qin K, Herms JW, et al. The cellular prion protein binds copper in vivo. Nature. 1997;390(6661):684-687.

19. Jackson GS, Murray I, Hosszu LL, et al. Location and properties of metal-binding sites on the human prion protein. Proc Natl Acad Sci U S A. 2001;98(15):8531-8535.

20. Brown DR, Sassoon J. Copper-dependent functions for the prion protein. Mol Biotechnol. 2002;22(2):165-1678.

21. Khosravani H, Zhang Y, Tsutsui S, et al. Prion protein attenuates excitotoxicity by inhibiting NMDA receptors. J Cell Biol. 2008;181(3): 551-565.

22. You $\mathrm{H}$, Tsutsui $\mathrm{S}$, Hameed $\mathrm{S}$, et al. $\mathrm{A} \beta$ neurotoxicity depends on interactions between copper ions, prion protein, and N-methyl-D-aspartate receptors. Proc Natl Acad Sci U SA. 2012;109(5):1737-1742.

23. Mastrianni JA. The genetics of prion diseases. Genet Med. 2010;12(4): 187-195.

24. Puoti G, Bizzi A, Forloni G, Safar JG, Tagliavini F, Gambetti P. Sporadic human prion diseases: molecular insights and diagnosis. Lancet Neurol. 2012;11(7):618-628.

25. Goldfarb LG, Petersen RB, Tabaton M, et al. Fatal familial insomnia and familial Creutzfeldt-Jakob disease: disease phenotype determined by a DNA polymorphism. Science. 1992;258(5083):806-808.

26. Ron D, Walter P. Signal integration in the endoplasmic reticulum unfolded protein response. Nat Rev Mol Cell Biol. 2007;8(7):519-529.

27. Harding HP, Zhang Y, Ron D. Protein translation and folding are coupled by an endoplasmic-reticulum-resident kinase. Nature. 1999; 397(6716):271-274.

28. Novoa I, Zeng H, Harding H, Ron D. Feedback inhibition of the unfolded protein response by GADD34-mediated dephosphorylation of eIF2 $\alpha . J$ Cell Biol. 2001;153(5):1011-1022.

29. Yoshida H, Matsui T, Yamamoto A, Okada T, Mori K. XBP1 mRNA is induced by ATF6 and spliced by IRE1 in response to ER stress to produce a highly active transcription factor. Cell. 2001;107(7): $881-891$.
30. Lee AH, Iwakoshi NN, Glimcher LH. XBP-1 regulates a subset of endoplasmic reticulum resident chaperone genes in the unfolded protein response. Mol Cell Biol. 2003;23(21):7448-7459.

31. Yoshida H, Haze K, Yanagi H, Yura T, Mori K. Identification of the cis-acting endoplasmic reticulum stress response element responsible for transcriptional induction of mammalian glucose-regulated proteins. Involvement of basic leucine zipper transcription factors. $J$ Biol Chem. 1998;273(50):33741-33749.

32. Haze K, Yoshida H, Yanagi H, Yura T, Mori K. Mammalian transcription factor ATF6 is synthesized as a transmembrane protein and activated by proteolysis in response to endoplasmic reticulum stress. Mol Biol Cell. 1999;10(11):3787-3799.

33. Li M, Baumeister P, Roy B, et al. ATF6 as a transcription activator of the endoplasmic reticulum stress element: thapsigargin stress-induced changes and synergistic interactions with NF-Y and YY1. Mol Cell Biol. 2000;20(14):5096-5106.

34. Hetz C, Russelakis-Carneiro M, Maundrell K, Castilla J, Soto C. Caspase-12 and endoplasmic reticulum stress mediate neurotoxicity of pathological prion protein. EMBO J. 2003;22(20):5435-5445.

35. Yoo BC, Krapfenbauer K, Cairns N, Belay G, Bajo M, Lubec G. Overexpressed protein disulfide isomerase in brains of patients with sporadic Creutzfeldt-Jakob disease. Neurosci Lett. 2002;334(3): 196-200.

36. Hetz C, Castilla J, Soto C. Perturbation of endoplasmic reticulum homeostasis facilitates prion replication. $J$ Biol Chem. 2007;282(17): 12725-12733.

37. Torres M, Castillo K, Armisén R, Stutzin A, Soto C, Hetz C. Prion protein misfolding affects calcium homeostasis and sensitizes cells to endoplasmic reticulum stress. PLoS One. 2010;5(12):e15658.

38. Shi Q, Dong XP. (Ctm)PrP and ER stress: a neurotoxic mechanism of some special PrP mutants. Prion. 2011;5(3):123-125.

39. Castilla J, Hetz C, Soto C. Molecular mechanisms of neurotoxicity of pathological prion protein. Curr Mol Med. 2004;4(4):397-403.

40. Ferreiro E, Resende R, Costa R, Oliveira CR, Pereira CM. An endoplasmic-reticulum-specific apoptotic pathway is involved in prion and amyloid-beta peptides neurotoxicity. Neurobiol Dis. 2006;23(3): 669-678.

41. Wang X, Shi Q, Xu K, et al. Familial CJD associated PrP mutants within transmembrane region induced $\mathrm{Ctm}-\mathrm{PrP}$ retention in ER and triggered apoptosis by ER stress in SH-SY5Y cells. PLoS One. 2011;6(1):e14602.

42. Rane NS, Kang SW, Chakrabarti O, Feigenbaum L, Hegde RS. Reduced translocation of nascent prion protein during ER stress contributes to neurodegeneration. Dev Cell. 2008;15(3):359-370.

43. Nunziante M, Ackermann K, Dietrich K, et al. Proteasomal dysfunction and endoplasmic reticulum stress enhance trafficking of prion protein aggregates through the secretory pathway and increase accumulation of pathologic prion protein. J Biol Chem. 2011;286(39):33942-33953.

44. Ma J, Wollmann R, Lindquist S. Neurotoxicity and neurodegeneration when PrP accumulates in the cytosol. Science. 2002;298(5599): 1781-1785.

45. Peters JM, Franke WW, Kleinschmidt JA. Distinct $19 \mathrm{~S}$ and $20 \mathrm{~S}$ subcomplexes of the $26 \mathrm{~S}$ proteasome and their distribution in the nucleus and the cytoplasm. J Biol Chem. 1994;269(10):7709-7718.

46. Lodish HBA, Matsudaira P, Kaiser CA, et al. Molecular Cell Biology. 5th ed. New York: WH Freeman and Co; 2004:66-72.

47. Baumeister W, Walz J, Zuhl F, Seemüller E. The proteasome: paradigm of a self-compartmentalizing protease. Cell. 1998;92(3):367-380.

48. Früh K, Gossen M, Wang K, Bujard H, Peterson PA, Yang Y. Displacement of housekeeping proteasome subunits by MHC-encoded LMPs: a newly discovered mechanism for modulating the multicatalytic proteinase complex. EMBO J. 1994;13:3236-3244.

49. Deriziotis P, André R, Smith DM, et al. Misfolded PrP impairs the UPS by interaction with the $20 \mathrm{~S}$ proteasome and inhibition of substrate entry. EMBO J. 2011;30(15):3065-3077.

50. Deriziotis P, Tabrizi SJ. Prions and the proteasome. Biochim Biophys Acta. 2008;1782(12):713-722. 
51. Kim BY, Olzmann JA, Barsh GS, Chin LS, Li L. Spongiform neurodegeneration-associated E3 ligase Mahogunin ubiquitylates TSG101 and regulates endosomal trafficking. Mol Biol Cell. 2007;18(4): $1129-1142$.

52. Lehman NL. The ubiquitin proteasome system in neuropathology. Acta Neuropathol. 2009;118:329-347.

53. Lloyd SE, Maytham EG, Pota H, et al. HECTD2 is associated with susceptibility to mouse and human prion disease. PLoS Genet. 2009;5(2):e1000383.

54. Mishra RS, Bose S, Gu Y, Li R, Singh N. Aggresome formation by mutant prion proteins: the unfolding role of proteasomes in familial prion disorders. J Alzheimers Dis. 2003;5(1):15-23.

55. Kristiansen M, Messenger MJ, Klöhn PC, et al. Disease-related prion protein forms aggresomes in neuronal cells leading to caspase activation and apoptosis. J Biol Chem. 2005;280(46):38851-38861.

56. Yorimitsu T, Nair U, Yang Z, Klionsky DJ. Endoplasmic reticulum stress triggers autophagy. J Biol Chem. 2006;281(40):30299-30304.

57. Ogata M, Hino S, Saito A, et al. Autophagy is activated for cell survival after endoplasmic reticulum stress. Mol Cell Biol. 2006;26(24): 9220-9231.

58. Bernales S, McDonald KL, Walter P. Autophagy counterbalances endoplasmic reticulum expansion during the unfolded protein response. PLoS Biol. 2006;4(12):e423.

59. Rubinsztein DC, DiFiglia M, Heintz N, et al. Autophagy and its possible roles in nervous system diseases, damage and repair. Autophagy. 2005;1(1):11-22.

60. Heiseke A, Aguib Y, Schatzl HM. Autophagy, prion infection and their mutual interactions. Curr Issues Mol Biol. 2010;12(2):87-97.

61. Boellaard JW, Schlote W, Tateishi J. Neuronal autophagy in experimental Creutzfeldt-Jakob's disease. Acta Neuropathol. 1989;78(4):410-418.

62. Boellaard JW, Kao M, Schlote W, Diringer H. Neuronal autophagy in experimental scrapie. Acta Neuropathol. 1991;82(3):225-228.

63. Schätzl HM, Laszlo L, Holtzman DM, et al. A hypothalamic neuronal cell line persistently infected with scrapie prions exhibits apoptosis J Virol. 1997;71(11):8821-8831.

64. Xu Y, Tian C, Wang SB, et al. Activation of the macroautophagic system in scrapie-infected experimental animals and human genetic prion diseases. Autophagy. 2012;8(11):1604-1620.

65. Cortes CJ, Qin K, Norstrom EM, Green WN, Bindokas VP, Mastrianni JA. Early delivery of misfolded PrP from ER to lysosomes by autophagy. Int J Cell Biol. 2013;2013:560421.

66. Cortes CJ, Qin K, Cook J, Solanki A, Mastrianni JA. Rapamycin delays disease onset and prevents PrP plaque deposition in a mouse model of Gerstmann-Sträussler-Scheinker disease. J Neurosci. 2012;32(36) 12396-12405.

67. Yun SW, Ertmer A, Flechsig E, et al. The tyrosine kinase inhibitor imatinib mesylate delays prion neuroinvasion by inhibiting prion propagation in the periphery. J Neurovirol. 2007;13(4):328-337.

68. Heiseke A, Aguib Y, Riemer C, Baier M, Schätzl HM. Lithium induces clearance of protease resistant prion protein in prion-infected cells by induction of autophagy. J Neurochem. 2009;109(1):25-34.

69. Aguib Y, Heiseke A, Gilch S, et al. Autophagy induction by trehalose counteracts cellular prion infection. Autophagy. 2009;5(3):361-369.

70. Yao H, Zhao D, Khan SH, Yang L. Role of autophagy in prion protein-induced neurodegenerative diseases. Acta Biochim Biophys Sin (Shanghai). 2013;45(6):494-502.

71. Wong E, Cuervo AM. Autophagy gone awry in neurodegenerative diseases. Nat Neurosci. 2010;13(7):805-811.

72. Belichenko PV, Brown D, Jeffrey M, Fraser JR. Dendritic and synaptic alterations of hippocampal pyramidal neurones in scrapie-infected mice. Neuropathol Appl Neurobiol. 2000;26(2):143-149.

73. Jeffrey M, Halliday WG, Bell J, et al. Synapse loss associated with abnormal PrP precedes neuronal degeneration in the scrapie-infected murine hippocampus. Neuropathol Appl Neurobiol. 2000;26(1):41-54.

74. Brown D, Belichenko P, Sales J, Jeffrey M, Fraser JR. Early loss of dendritic spines in murine scrapie revealed by confocal analysis. Neuroreport. 2001;12(1):179-183.
75. Cunningham C, Deacon R, Wells H, et al. Synaptic changes characterize early behavioural signs in the ME7 model of murine prion disease. Eur J Neurosci. 2003;17(10):2147-2155.

76. Chiti Z, Knutsen OM, Betmouni S, Greene JR. An integrated, temporal study of the behavioural, electrophysiological and neuropathological consequences of murine prion disease. Neurobiol Dis. 2006;22(2):363-373.

77. Mallucci GR, White MD, Farmer M, et al. Targeting cellular prion protein reverses early cognitive deficits and neurophysiological dysfunction in prion-infected mice. Neuron. 2007;53(3):325-335.

78. Gray BC, Siskova Z, Perry VH, O'Connor V. Selective presynaptic degeneration in the synaptopathy associated with ME7-induced hippocampal pathology. Neurobiol Dis. 2009;35(1):63-74.

79. Sisková Z, Page A, O'Connor V, Perry VH. Degenerating synaptic boutons in prion disease: microglia activation without synaptic stripping. Am J Pathol. 2009;175(4):1610-1621.

80. Moreno JA, Radford H, Peretti D, et al. Sustained translational repression by eIF $2 \alpha-\mathrm{P}$ mediates prion neurodegeneration. Nature. 2012;485(7399):507-511.

81. Moreno JA, Halliday M, Molloy C, et al. Oral treatment targeting the unfolded protein response prevents neurodegeneration and clinical disease in prion-infected mice. Sci Transl Med. 2013;5(206):206ra138.

82. Mukherjee A, Morales-Scheihing D, Gonzalez-Romero D, Green K, Taglialatela G, Soto C. Calcineurin inhibition at the clinical phase of prion disease reduces neurodegeneration, improves behavioral alterations and increases animal survival. PLoS Pathog. 2010;6(10):e1001138.

83. Stewart RS, Piccardo P, Ghetti B, Harris DA. Neurodegenerative illness in transgenic mice expressing a transmembrane form of the prion protein. J Neurosci. 2005;25(13):3469-3477.

84. Quaglio E, Restelli E, Garofoli A, et al. Expression of mutant or cytosolic PrP in transgenic mice and cells is not associated with endoplasmic reticulum stress or proteasome dysfunction. PLoS One. 2011;6(4):e19339.

85. Biasini E, Massignan T, Fioriti L, et al. Analysis of the cerebellar proteome in a transgenic mouse model of inherited prion disease reveals preclinical alteration of calcineurin activity. Proteomics. 2006;6(9):2823-2834.

86. Ahmad ZA, Yeap SK, Ali AM, Ho WY, Alitheen NB, Hamid M. scFv antibody: principles and clinical application. Clin Dev Immunol. 2012;2012:980250.

87. Malone J, Sullivan MA. Analysis of antibody selection by phage display utilizing anti-phenobarbital antibodies. J Mol Recognit. 1996;9(5-6): 738-745.

88. Huang L, Su X, Federoff HJ. Single-chain fragment variable passive immunotherapies for neurodegenerative diseases. Int $J$ Mol Sci. 2013;14(9):19109-19127.

89. Filesi I, Cardinale A, Mattei S, Biocca S. Selective re-routing of prion protein to proteasomes and alteration of its vesicular secretion prevent $\operatorname{PrP}(\mathrm{Sc})$ formation. J Neurochem. 2007;101(6):1516-1526.

90. Cardinale A, Filesi I, Vetrugno V, Pocchiari M, Sy MS, Biocca S. Trapping prion protein in the endoplasmic reticulum impairs PrPC maturation and prevents PrPSc accumulation. J Biol Chem. 2005;280(1): 685-694.

91. Biocca S, Ruberti F, Tafani M, Pierandrei-Amaldi P, Cattaneo A. Redox state of single chain Fv fragments targeted to the endoplasmic reticulum, cytosol and mitochondria. Biotechnology (NY). 1995;13(10): $1110-1115$.

92. Cardinale A, Biocca S. Gene-based antibody strategies for prion diseases. Int J Cell Biol. 2013;2013:710406.

93. Wuertzer CA, Sullivan MA, Qiu X, Federoff HJ. CNS delivery of vectored prion-specific single-chain antibodies delays disease onset. Mol Ther. 2008;16(3):481-486.

94. Donofrio G, Heppner FL, Polymenidou M, Musahl C, Aguzzi A. Paracrine inhibition of prion propagation by anti-PrP single-chain $\mathrm{Fv}$ miniantibodies. J Virol. 2005;79(13):8330-8338.

95. Fujita K, Yamaguchi Y, Mori T, et al. Effects of a brain-engraftable microglial cell line expressing anti-prion scFv antibodies on survival times of mice infected with scrapie prions. Cell Mol Neurobiol. 2011; 31(7):999-1008. 
96. Gauczynski S, Hundt $\mathrm{C}$, Leucht $\mathrm{C}$, Weiss S. Interaction of prion proteins with cell surface receptors, molecular chaperones, and other molecules. Adv Protein Chem. 2001;57:229-272.

97. Gauczynski S, Nikles D, El-Gogo S, et al. The 37-kDa/67-kDa laminin receptor acts as a receptor for infectious prions and is inhibited by polysulfated glycanes. J Infect Dis. 2006;194(5):702-709.

98. Vana K, Weiss S. A trans-dominant negative $37 \mathrm{kDa} / 67 \mathrm{kDa}$ laminin receptor mutant impairs $\mathrm{PrP}(\mathrm{Sc})$ propagation in scrapie-infected neuronal cells. J Mol Biol. 2006;358(1):57-66.

99. Ludewigs H, Zuber C, Vana K, Nikles D, Zerr I, Weiss S. Therapeutic approaches for prion disorders. Expert Rev Anti Infect Ther. 2007;5(4): 613-630.

100. Morel E, Andrieu T, Casagrande F, et al. Bovine prion is endocytosed by human enterocytes via the $37 \mathrm{kDa} / 67 \mathrm{kDa}$ laminin receptor. $A m \mathrm{~J}$ Pathol. 2005;167(4):1033-1042.

101. Zuber C, Knackmuss S, Rey C, et al. Single chain Fv antibodies directed against the $37 \mathrm{kDa} / 67 \mathrm{kDa}$ laminin receptor as therapeutic tools in prion diseases. Mol Immunol. 2008;45(1):144-151.

102. Zuber C, Mitteregger G, Schuhmann N, et al. Delivery of single-chain antibodies (scFvs) directed against the $37 / 67 \mathrm{kDa}$ laminin receptor into mice via recombinant adeno-associated viral vectors for prion disease gene therapy. J Gen Virol. 2008;89(Pt 8):2055-2061.

103. Jiang P, Gan M, Ebrahim AS, Lin WL, Melrose HL, Yen SH. ER stress response plays an important role in aggregation of $\alpha$-synuclein. Mol Neurodegener. 2010;5:56.

104. Colla E, Jensen PH, Pletnikova O, Troncoso JC, Glabe C, Lee MK. Accumulation of toxic $\alpha$-synuclein oligomer within endoplasmic reticulum occurs in $\alpha$-synucleinopathy in vivo. J Neurosci. 2012;32(10): 3301-3305.
105. Colla E, Coune P, Liu Y, et al. Endoplasmic reticulum stress is important for the manifestations of $\alpha$-synucleinopathy in vivo. J Neurosci. 2012;32(10):3306-3320.

106. Lee DY, Lee KS, Lee HJ, et al. Activation of PERK signaling attenuates Abeta-mediated ER stress. PLoS One. 2010;5(5):e10489.

107. Reijonen S, Putkonen N, Nørremølle A, Lindholm D, Korhonen L. Inhibition of endoplasmic reticulum stress counteracts neuronal cell death and protein aggregation caused by N-terminal mutant huntingtin proteins. Exp Cell Res. 2008;314(5):950-960.

108. Nakka VP, Gusain A, Raghubir R. Endoplasmic reticulum stress plays critical role in brain damage after cerebral ischemia/reperfusion in rats. Neurotox Res. 2010;17(2):189-202.

109. Halliday M, Mallucci GR. Targeting the unfolded protein response in neurodegeneration: A new approach to therapy. Neuropharmacology. 2014;76(Pt A):169-174.

110. Chiesa R, Piccardo P, Quaglio E, et al. Molecular distinction between pathogenic and infectious properties of the prion protein. $J$ Virol. 2003;77(13):7611-7622.

111. Sandberg MK, Al-Doujaily H, Sharps B, Clarke AR, Collinge J. Prion propagation and toxicity in vivo occur in two distinct mechanistic phases. Nature. 2011;470(7335):540-542.

112. Silveira JR, Raymond GJ, Hughson AG, et al. The most infectious prion protein particles. Nature. 2005;437(7056):257-261.

113. Simoneau $\mathrm{S}$, Rezaei $\mathrm{H}$, Salès $\mathrm{N}$, et al. In vitro and in vivo neurotoxicity of prion protein oligomers. PLoS Pathog. 2007;3(8):e125.
Research and Reports in Biochemistry

\section{Publish your work in this journal}

Research and Reports in Biochemistry is an international, peer-reviewed, open access journal publishing original research, reports, reviews and commentaries on all areas of biochemistry. The manuscript management system is completely online and includes a very quick and fair
Dovepress

peer-review system. Visit http://www.dovepress.com/testimonials.php to read real quotes from published authors. 